\title{
Analysis of the Benefits of Implementation of IPD for Construction Project Stakeholders
}

\author{
Mahdi Alinezhad ${ }^{\text {a }}$, Ehsan Saghatforoush ${ }^{b^{*}}$, Zahra Kahvandi ${ }^{c}$, Christopher Preece ${ }^{\mathrm{d}}$ \\ ${ }^{a}$ MSc, Department of Project and Construction Management, University of Tehran, Tehran, Iran. \\ ${ }^{b}$ Senior Lecturer, School of Construction Economics and Management, University of the Witwatersrand, Johannesburg, South Africa. \\ ${ }^{c}$ MSc, Department of Project and Construction Management, MehrAlborz University (MAU), Tehran, Iran. \\ ${ }^{d}$ Professor, Centre on Sustainable Built Environment, Abu Dhabi University, Abu Dhabi, United Arab Emirates.
}

Received 04 March 2020; Accepted 30 June 2020

\begin{abstract}
The greatest challenges for construction infrastructure projects are those related to increasing problems of managing the time and cost in project implementation. For many years, new methods have been used to reduce the problems to do with separation of design from the implementation stage. An important point is that all projects tend to require integration; however, it has been observed that construction projects usually enjoy the benefits and capacities of updated methods and technologies later than other industries. One of these approaches, which have been growing in developed countries for some time, is using the Integrated Project Delivery (IPD) approach. Using such an approach has various benefits, but also would seem to pose significant challenges. To-date, it and has not still achieved success in terms of legal recognition and wider implementation. The aim of this study is to extract the benefits of the implementation of the IPD approach using an in-depth literature review. Then descriptive analysis is applied to identify the benefits of IPD. The benefits of applying this approach for key construction project stakeholders are classified using pattern analysis. This study has offered a framework in order to present available generic and specific benefits to each project stakeholder, and it provides the required motivation for project owners to use and implement it in their future projects. Moreover, they should understand the important factors that lead to IPD adoption. They can use this information to develop a contractual framework to make it more effective.
\end{abstract}

Keywords: Integrated Project Delivery; Benefits, Infrastructure Projects; Key Project Stakeholders; Construction Industry.

\section{Introduction}

Recent studies have shown inefficiency and waste of resources in the construction industry. One of these studies is an article published in the Economist journal. In the USA from the year 2000, 30\% of the waste of resources may be attributed to the construction industry [1]. Research conducted by the American Energy Organization, suggested that the construction industry and building manufacturing processes in the USA is responsible for nearly $48 \%$ of annual energy consumption and 76\% of annual power consumption [2]. Another study conducted from 2004 indicates that the lack of appropriate software for engineers and architects results in annual extra costs of more than 16 Billion dollars. Since 1964 onward, the construction industry has experienced a downturn in efficiency and productivity; this is while other industries have had a $200 \%$ growth [1]. Studies show that $57 \%$ of effort creates no added value in the construction industry. In contrast, in the manufacturing industry, this figure is $26 \%$. This would seem to indicate the

${ }^{*}$ Corresponding author: ehsan.saghatforoush@wits.ac.za

http://dx.doi.org/10.28991/cej-2020-03091570

(C) 2020 by the authors. Licensee C.E.J, Tehran, Iran. This article is an open access article distributed under the terms and conditions of the Creative Commons Attribution (CC-BY) license (http://creativecommons.org/licenses/by/4.0/). 
low productivity of the construction industry in comparison with other industries [2]. New and diverse technologies have been created, if applied well and accompanied by participatory processes, which can bring significant growth in productivity for the construction industry, and result in reduced requests for information revisions, time and cost wastage. Project owners are looking for methods to achieve these outputs [1]. As a result of the construction industry development, project owners believe that without considering interpersonal relationships and human aspects, problems in the construction industry cannot be resolved; so they turned to partnerships [2]. However for the effective implementation of partnering in projects, traditional processes of selecting contractors cannot be used. Although partnering principles, and also using Total Quality Management (TQM), achieved some positive results, if traditional contracts are used, all the potential benefits of partnering cannot be realized. Lack of proper contractual mechanisms for implementing partnering would seem to illustrate the need for using a kind of multilateral single contract [3].

By increasing the complexity of buildings and specialization, there is a need for a new system, which enables the goals of improved cost, time, and quality to be achieved. This has prompted the creation of Integrated Project Delivery (IPD) [4]. IPD helps create partnering in projects through multilateral single contracts [3]. This new approach, through benefiting from the participatory method, improves project outputs and objectives [4]. IPD is an approach in delivery of construction projects, which integrates individuals, systems, knowledge, and experience. It reduces cost, time, and rework and thus, increases the value for the building owner. The focus of such integration is empowering the partnering, while partnering is the main component of building mutual respect and trust in the project team [5]. Teamwork is created in projects by benefiting from common values, and mutual respect. Contracts based on IPD are appropriate for building trust, commitment, and transparency in complex projects [6]. The trust of key stakeholders in IPD is very important, as well as the benefits of IPD because it has to be superior to previous systems to persuade them to accept. In the public sector, even though in IPD the quality criteria is considered higher than under the traditional methods, the strict rules and policies harm all the processes. However, it is predicted to increase in the upcoming years [7].

To-date, only a small number of studies have been conducted on the benefits of IPD [8,9], and no documented study has been conducted to analyze and classify the benefits of implementing this method based on objectives and challenges to each key project stakeholder in construction. This research classifies the benefits to key project stakeholders in implementing the IPD approach obtained from available literature and international case studies. The benefits of applying this approach for key construction project stakeholders are classified using pattern analysis. This study offers a framework in order to present available generic and specific benefits to each project stakeholder, and it provides the required motivation for project owners to use and implement it in their future projects. Moreover, project owners should understand the important factors that lead to IPD adoption. They can use this information to develop a contractual framework to make it more effective. The next section considers the literature review, followed by the method of research and data analysis and finally discussion and conclusions.

\section{Literature Review}

In this section, the definitions related to IPD are reviewed, also status of existing contracts are illustrated.

\subsection{Integrated Project Delivery (IPD)}

The definition by the American Institute of Architects states that IPD integrates individuals, systems, commercial structures, and activities related to construction projects in the form of a process. This approach, while attracting partnering and aligning viewpoints of all project stakeholders, results in improved project results, increased value for owners, reduced wastes, and increased efficiency in all phases of design, pre-construction and construction [1]. In other words, IPD is a commercial model for designing, implementing, and delivering projects by using participatory and integrated teams from all involved parties in the project, such as owner, designer, contractor, manufacturer, and supplier [10].

IPD is based on two categories of behavioral and contractual principles. Contractual principles of IPD include equal rights for all stakeholders, common profit and loss, equal responsibilities, early involvement of stakeholders, development of project objectives collectively, and collective decisions. Behavioral principles of IPD include mutual respect and trust, members' willingness to cooperate, and open communications [1, 7]. Although IPD is still not widely applied in projects, case studies indicate the success of this approach for project key stakeholders. The results obtained from implementing IPD or IPD-ish contracts in 6 case studies, published by the American Institute of Architects in 2010, indicates that a higher level of owner expectations has been met as a result of implementing this approach, including cost, time, quality, and sustainability concerns [11, 12]. This study conducted on more projects in 2012, and incentives for using IPD were stated as market advantages, cost predictability, time predictability, risk management, and technical complexities [13].

There are some factors that lead the construction industry toward using the IPD approach. These factors include market demand, the need to increase productivity in the construction industry, existing demand from $\mathrm{A} / \mathrm{E} / \mathrm{C}$, and 
increasing complexity of existing buildings, technology development, sustainability considerations, and participatory way of current projects $[14,15]$. On the other hand, owners of projects are looking to use integrated practices such as IPD because of some perceived benefits such as improved decision-making, improved contracts' documentary, improved pre-construction estimations, better timing and provision, more coordination, cost effectiveness, and improved documentations of project close phase [14]. This integrated approach seeks to achieve goals such as predictable outputs, resolving lack of coordination among project team members, improved data sharing by using tools such as Building Information Modeling (BIM), integration of project team members, and creating a culture of participation [15, 16]. Ilozor and Kelly [8] classified benefits of IPD and partnering by collecting and reviewing the previous literature. Although research about the trend of studies related to the benefits of IPD implementation indicates increasing growth of the construction industry by this modern method [17], most of the construction projects in which IPD is utilized, relates to ultra-complex and large buildings such as hospitals and research labs [18, 19]. IPD has only been applied in a small number of projects [11]. The main reason would appear to relate to the structural and administrative mismatch of traditional contracts with an integration attitude required in IPD, which will be discussed in the next section.

\subsection{Status of Existing Contracts: The Need to Move Toward IPD Approach}

According to the definition provided in the Merriam-Webster dictionary, the term "infrastructure" refers to structures and equipment required for appropriate performance of an organization, region, and country [20]. Construction projects play a major role in infrastructure. Due to inefficiency and more waste of resources in the construction industry than other industries $[1,21]$, a special focus on increasing productivity would seem to be necessary [1]. The United Kingdom's Office of Government Commerce (UKOGC) in a research conducted about projects' construction cost, asserted that about $30 \%$ of projects' construction cost is reversible via improvement obtained from teams' integration [22]. New technologies, if applied properly, can reduce waste of resources and extra costs, and improve outputs [1]. One of these approaches is the integration attitude in project delivery.

This approach improves project outputs and delivers more successful projects by integrating existing systems, individuals, and knowledge [5], and by benefiting from participatory method [4]; however the prevailing attitude in existing traditional contracts is a different attitude, and in some cases, completely opposed to this attitude. In recent research in infrastructure projects, by increasing system integration a higher sustainability is achieved. In these projects, the effect of project delivery systems and the procurement procedures were studied. Conducted researches show that integration level has a direct impact on projects' sustainability level. When the project delivery system goes toward integration, an attainable level in sustainability standards increases too [23]. In addition the level of integration has a direct impact on the final project outcomes, particularly on the sustainability objectives [24]. The significant issue is that integration leads to increasing efficiency of work force, and is the most important tool for improving parameters of project delivery [25]. Such participation and communication between the project team has significant effects on project success [26] that shows the need for integration.

Design Bid Build (DBB), also known as traditional contracts, are still considered by many owners and clients, and due to its more understandable processes, public and private owners use this kind of contracts regularly [27]. In these contracts design and construction phases are completely separated from each other [1] and this is the biggest problem in using such kind of contracts, because reworks due to design revision causes reduction of project efficiency. Based on studies, rework as the most common problem in construction process, leads to 4 to 12 percent increase in costs [28, 29]. Also, in traditional contracts, designers are responsible for designing and contractors are responsible for construction, and this issue is accompanied with separation in design and construction. In terms of participation and cooperation, one of the most important weaknesses of traditional methods of such project delivery systems is that the financial success of project stakeholders do not depend on project success [1]. Unlike traditional project delivery systems, such as DBB, which selects the winner based on the lowest price, in the IPD approach this is decided based on the best attainable value $[30,31]$.

In previous studies, participatory delivery systems have been found to have a higher reliability in costs than traditional ones. This is because of uncertainty in traditional systems which is much higher than participatory methods, and it is suggested that in complex and risky projects, participatory delivery systems such as construction manager at risk should be used [18]. Weaknesses of traditional delivery systems, such as wrong cost estimations, designs without stakeholder`s coordination, inefficient processes of information request, and financial claims, lead the construction industry toward participatory practices. Using IPD approach is a response to such traditional systems weaknesses [32]. Table 1 presents a comparison between traditional systems of project delivery and IPD. 
Table 1. Traditional project delivery systems vs. IPD [1]

\begin{tabular}{|c|c|c|}
\hline Traditional Project Delivery & & Integrated Project Delivery \\
\hline $\begin{array}{l}\text { Fragmented, assembled on "just-as- } \\
\text { needed" or "minimum-necessary" basis, } \\
\text { strongly hierarchical, controlled }\end{array}$ & Teams & $\begin{array}{l}\text { An integrated team entity composed key project } \\
\text { stakeholders, assembled early in the process, open, } \\
\text { collaborative }\end{array}$ \\
\hline $\begin{array}{l}\text { Linear, distinct, segregated; knowledge } \\
\text { gathered "just-as-needed"; information } \\
\text { hoarded; silos of knowledge and expertise }\end{array}$ & Process & $\begin{array}{l}\text { Concurrent and multi-level; early contributions of } \\
\text { knowledge and expertise; information openly } \\
\text { shared; stakeholder trust respect }\end{array}$ \\
\hline $\begin{array}{l}\text { Individually managed, transferred to the } \\
\text { greatest extent possible }\end{array}$ & Risk & Collectively managed, appropriately shared \\
\hline $\begin{array}{l}\text { Individually pursued; minimum effort for } \\
\text { maximum return; (usually) first-cost based }\end{array}$ & $\begin{array}{l}\text { Compensation/ } \\
\text { reward }\end{array}$ & Team success tied to project success; value-based \\
\hline Paper-based, 2 dimensional; analog & $\begin{array}{l}\text { Communications/ } \\
\text { technology }\end{array}$ & $\begin{array}{l}\text { Digitally based, virtual; building information } \\
\text { modeling ( } 3,4 \text { and } 5 \text { dimensional) }\end{array}$ \\
\hline $\begin{array}{l}\text { Encourage unilateral effort; allocate and } \\
\text { transfer risk; no sharing }\end{array}$ & Agreements & $\begin{array}{l}\text { Encourage, foster, promote and support multi- } \\
\text { lateral open sharing and collaboration; risk sharing }\end{array}$ \\
\hline
\end{tabular}

Table 1 shows that IPD improves communication by integrating individuals, systems, and processes in the form of multilateral contracts. In addition, it manages project risk, by participation of all the project stakeholders. Generally, project owners define integration and participation levels in projects, and in this regard, in comparison with other stakeholders, they play a key role. There are three types of integration in projects: participation level 1 or public participation, which is not mentioned in the provisions of the contract; participation level 2, which is an advanced participation and in some of the provisions of the contract, participation by stakeholders is required; participation level 3 , which is provided as necessary in multilateral contracts between all stakeholders. Participation level 3 indicates comprehensive integration of systems, individuals, and processes. Table 2 shows these three levels of participation and project delivery systems for each of these levels [2].

Table 2. Participation and Cooperation levels [2]

\begin{tabular}{|c|c|c|c|}
\hline & $\begin{array}{c}\text { Level One } \\
\text { "Typical" Collaboration }\end{array}$ & $\begin{array}{c}\text { Level Two } \\
\text { "Enhanced" Collaboration }\end{array}$ & $\begin{array}{c}\text { Level Three } \\
\text { "Required" Collaboration }\end{array}$ \\
\hline Level of Collaboration & Lower & $\longleftrightarrow$ & Higher \\
\hline $\begin{array}{l}\text { Philosophy or delivery } \\
\text { method? }\end{array}$ & IPD as a Philosophy & IPD as a Philosophy & IPD as a Delivery Method \\
\hline Also known as ... & N/A & $\begin{array}{l}\text { IPD-ish; IPD Lite; Non } \\
\text { Multi=party IPD; } \\
\text { Technology Enhanced } \\
\text { Collaboration; Hybrid IPD; } \\
\text { Integrated Practice }\end{array}$ & $\begin{array}{l}\text { Multi-Party Contracting; "Pure" } \\
\text { IPD; Relational Contracting; } \\
\text { Alliancing; Lean Project } \\
\text { Delivery System TM }\end{array}$ \\
\hline Delivery Approaches & $\mathrm{Cm}$ at-risk or Design-Build & $\mathrm{Cm}$ at-risk or Design-Build & Integrated Project Delivery \\
\hline Typical Selection Process & $\begin{array}{c}\text { Qualification Based Selection } \\
\text { of all team members or Best } \\
\text { Value Proposal }\end{array}$ & $\begin{array}{l}\text { Qualifications Based } \\
\text { Selection of all team } \\
\text { members }\end{array}$ & $\begin{array}{l}\text { Qualifications Based Selection } \\
\text { of all team members }\end{array}$ \\
\hline Nature of Agreement & Transactional & Transactional & Relational \\
\hline Key Characteristics & $\begin{array}{l}\text { - No contract language } \\
\text { requiring collaboration } \\
\text { - Limited team risk sharing } \\
\text { - } \mathrm{CM} \text { or DB share in saving }\end{array}$ & $\begin{array}{l}\text { - Contract language } \\
\text { requiring collaboration } \\
\text { - Some team risk sharing } \\
\text { - Co-location of team }\end{array}$ & $\begin{array}{l}\text { - Owner-Designer-Contractor } \\
\text { (and possibly other key team } \\
\text { members-IPD Subs) all sign } \\
\text { one contract that contractors } \\
\text { collaboration } \\
\text { - Team risk-sharing-incl. A/E } \\
\text { - Team decision-making } \\
\text { - Optimizing the Whole } \\
\text { - Pain / Gain sharing } \\
\text { - Limits on litigation } \\
\text { - Co-location of the team }\end{array}$ \\
\hline $\begin{array}{l}\text { Typical Basis of } \\
\text { Reimbursement }\end{array}$ & GMP & GMP & $\begin{array}{l}\text { GMP or No GMP (some costs } \\
\text { guaranteed) }\end{array}$ \\
\hline
\end{tabular}


This table illustrates that as IPD-ish delivery systems, such as DB and CM@R, tend to completely integrated systems, participation increases. Active participation of client and the owner of the project in decision making process during design and construction phases increase the probability of achieving success in the project. From this perspective, DB and CM@R methods have some problems, while using IPD approach realizes this issue. From another perspective, early involvement of project key stakeholders is considered as its advantage over DB method, which results in creating objectives and project value which is approved by all key stakeholders. This advantage puts this method in the group of methods with high reliability. Shared Pain or Gain, considered as IPD principles, is against DB contracts' principles, links success of each of the key stakeholders to project success. This increases the interest of designer and contractor, for achieving project objectives, significantly [32].

IPD was used in a healthcare project in Denver, Colorado, with a building size of $430000 \mathrm{SF}$ and $\$ 160$ million cost and with a 24 months schedule. During conducted investigations, project completion was estimated with $13 \%$ cost reduction by using DBB method and 17\% cost reduction by using DB and CMR methods. Finally, the IPD method was conducted with a cost reduction of 26\% [34]. In other healthcare projects in San Francisco, IPD implementation provides the possibility of presence of maintenance contractors at the beginning of the project. In this way, about $\$ 1$ million was saved in the electrical equipment sector, and about $\$ 5$ million in the mechanical sector. In the medical center building in Fairfield, the initial funding was estimated as $\$ 22,250,000$ which was decreased to $\$ 19,437,600$ after agreements among project owner and contractor and designer, through implementing IPD method [13]. London Heathrow Terminal 5, is one of the most successful complex projects that was successful in providing the determined objectives by applying IPD principles, and was completed in 2008 with a budget of $£ 4.3$ Billion [35]. What made this project successful was focus on three issues of logistics system, culture, and mutual trust. One of the main values of T5 was teamwork and sharing project objective instead of individual objectives [36, 37]. Using the lessons learned from T5, British construction industry owners started 2012 Olympic set of projects of London. This megaproject was started with a $£ 7.2$ billion budget. Using the integration system, it could be one of the safest and most sustainable projects and was completed in 2010 with the exact budget. Although IPD principles in it were not as successful as T5, because of diversity in working activities, we can point to one of the greatest cost reductions with $£ 350$ million reduction and design of $£ 300$ million [38].

According to the problems of IPD-ish approaches such as DB and CM@R, these contracts do not have the possibility of providing comprehensive participation for all key stakeholders of the project. On the other hand, construction industry contracts require fundamental changes to use the benefits of integration and partnering approaches. So it is required to extract benefits of implementing the IPD approach and classify them in the form of each of key project stakeholders. In the next section, the research methodology and the process to extract and classify the IPD benefits are presented.

\section{Research Methodology}

Research is a regular practice of obtaining responses to the raised questions on a selected topic [39]. This study is applied research, from an objective point of view. In terms of data collection, it is a qualitative research. The results of this are used in decision-making and policy-making, as well as planning. The aim of qualitative research is gaining concepts and collecting data, such that they emerge in theories. Data analysis is a multi-stage process, during which data is collected through applying data collection tools, is summarized, codified, classified, and finally processed. This is done to provide the area of establishing several kinds of analysis and communications between data to test hypotheses. In qualitative research, the distinction between analysis and interpretation is not very clear, but a broad perspective can be provided.

Statistical analysis are of two kinds: descriptive analysis and inferential analysis [40]. In this study, in order to extract benefits of applying IPD in different studies or cases, descriptive analysis is used for codifying. In this type of analysis, by accessing records that are rooted in the past and present, it is possible to analyze data based on past and present events and generate insights. Then through using pattern analysis, these codes are classified separately for each key stakeholder of the project, including owner, designer, and contractor. Also, in the present study, in order to facilitate performing qualitative analysis and classifying library studies, Nvivo software is used.

\section{Results and Discussion}

In this section, identifying the benefits obtained from IPD implementation is presented in two sections. First, potential benefits achieved by IPD implementation are extracted from the research literature. Second, benefits obtained by implementing IPD are stated that were realized through case studies. These benefits are different for various project stakeholders. They have different importance levels for different parties involved in construction projects. 


\subsection{Potential Benefits of IPD Implementation}

IPD has the integrated knowledge of all project team members. This integrated knowledge is used in all project phases [41]. By IPD implementation, all project stakeholders enjoy its various benefits such as facility managers, end users, contractors, and suppliers who have early participation at planning and design. Processes are outcome-centered, and decisions are not made individually and just based on costs. All communications are clear, open, and based on mutual trust. Designers observe consequences of their decisions at design phase. Risks and rewards are based on values, and are distributed according to the efforts of stakeholders to achieve this value. And eventually, a sustainable project with higher quality is delivered [1].

One of the basic benefits of IPD is early participation of key stakeholders in the project in the early phases of project design [4]. IPD implementation has some benefits for owners such as sharing knowledge in the early phases of the project and providing the possibility of achieving the goals. Such integrated system increases project team perception of outputs considered by owners. The project team will be able to manage and control project costs that facilitate achieving project goals, including time, cost, quality, and sustainability [1].

Owners achieve the potential benefits by using an integrated attitude. Early presence of the owner in the planning and design stages, leads to a construction phase with higher quality and financial productivity. This early presence and involvement in the design phase, results in the possibility of more precise planning, a better understanding of the project, and reduction of problems related to construction in design phase. However, this leads to more precise control of costs and achieving pre-defined project objectives [1].

The integration process allows designers to enjoy experience of sharing ideas with construction contractors in the early phases of planning and design as well as provide plans with higher precision and lower problems. This increases quality of the plan and the project. Early participation of contractors is associated with reduced time for documentation, which facilitates achieving time, cost, and quality objectives of the project [2]. In a completely integrated project, decisions are made by pre-determined decision-making core that facilitates conclusion and reduces faults due to single person decisions [1].

Unlike traditional contracts, in the IPD approach, designers and constructors have mutual responsibilities in the design and construction phases [2]. Benefits obtained from IPD implementation include early participation, implementing planning and control system, shared contractual risk and reward, integrated leadership, and using participatory software [42]. Selecting the IPD approach as a project delivery system, is one of the key factors for project success [25]. By using the IPD approach, all decisions are made based on 'Best for Project' theory and it guarantees achieving the most appropriate results [41]. Through using the IPD approach, general purposes will be determined according to mutual participation of project key stakeholders, which deliver the final product better to the client and the owner [43].

The most important and recognized benefit of IPD is participation of all project stakeholders in the early phases of design [44]. This participation leads to formation of better relationships among the owner, designer, and contractor. Its processes lead to creating long-term relations between project stakeholders. In this system, all stakeholders work on the project in the best way, which finally will show its advantage, too [43]. Unlike traditional methods of project delivery systems, IPD combines risks and rewards. This provides an incentive for more participation in the project to achieve project objectives [44]. Using this new approach leads to cost reduction, more intensive timing, and risk reduction of changes [15]. Cost in IPD implemented projects is significantly lower than the other systems [45]. Other benefits of it are: improving cost management processes before bidding, which this is obtained by using cost integrated processes in IPD contracts [46]. In IPD, individuals' financial success depends on project success. Therefore, project key stakeholders, by trying to achieve their objectives, move toward project success unconsciously [1].

Other potential benefits of IPD are reducing construction time because of intensive planning. This is because of the early ordering of required procurements before completion of the design phase [2]. In projects employing complete integration (participation and integration level 3), interests and cultures are aligned, everyone focuses on the project, participation is formed in the early phases and continues during the project, problems are identified quickly, and are analyzed and solved carefully. In addition, waste reduces, changes reduce greatly or disappear, claims and disputes are resolved, project timing improves, and all project stakeholders are satisfied with the achieved results. The objectives are aligned and the ability to resolve problems are improved [47]. The IPD benefits in the construction phase refer to time reduction and waste of resources [43].

Another important benefit of the IPD approach is replacing value engineering with Target Value Design (TVD). This means that in the early phases of the project, the project team agrees on the available budget that meets the goals of the project owner, and by the way the project should be completed within this budget [1]. By employing IPD and its principles that leads to comprehensive participation of contractors, designers, suppliers, and owner of the project, not 
only the time is reduced, but also the project total value will go beyond its maximum value in traditional contracts [30].

The IPD approach also allows using sustainability goals in projects. The issue is not seen in traditional contracts [47]. IPD implementation provides a better opportunity for problems related to sustainability [15].

In the IPD approach, there is just one contract for all parties involved in a project. This single contract increases the possibility of project stakeholders' participation and coordination properly, and project stakeholders will not be confused with several kinds of contracts existing in traditional systems. This will also reduce complexity [4]. By true implementation of IPD, one can achieve cost reduction after completion of the construction period, i.e. operation, maintenance and waste of resources. Participation of all parties involved in the project during the project, results in a reduction of requests for information and change orders in all phases of the project [43].

In a study conducted in 2010 through interviews with experts and people involved directly in IPD projects, the benefits of using IPD were identified as follows: reduction in change orders, cost saving, more compressed time, fewer Requests for Information (RFI), higher quality of the final product, and higher productivity [44]. Among the benefits of IPD, we can point to providing the possibility of using integration software such as Building Information Modelling (BIM). There is no requirement to simultaneously use these in projects, but using them simultaneously reveals their benefits better [22]. Employing the IPD approach facilitates using the most updated technologies and tools such as BIM. Their simultaneous use will lead to the emergence of synergy, which is associated with more output [1]. Using IPD and BIM resolves two main problems of increasing trend of integrated approaches and increased efficiency, which are contract, and process of coordinating design, supply, and construction [48].

IPD is appropriate for projects of different sizes. But most researchers believe that this system brings more tangible results for projects with medium to large scale. In terms of the nature of construction projects appropriate for IPD implementation, health sector projects are seen to be the most suitable ones, because modification of contracts in the health projects has complexities and includes various equipment etc. Consequently, it has complex construction and operation phases. Using the IPD approach is beneficial for such projects. The best implementation system for unique large projects is IPD [44, 49]. The next section will attempt to investigate benefits obtained from actual IPD implementation in available case studies.

\subsection{Actual Existing Benefits of IPD Implementation in Case Studies}

One of the most important challenges in IPD implementation is the small amount of data and qualitative results obtained from implementing this method in projects. Most of the documents have been literature reviews rather than showing the quantitative results obtained from cost and time reduction for example. In a study conducted to compare the benefits of using project delivery systems based on degree of integration (traditional systems, IPD-ish systems, IPD), at first indices of efficiency of project delivery systems were defined, and then the results obtained from implementing these indices in case studies were extracted. These results show that IPD-centered projects have higher quality than projects with other attitudes other than IPD. IPD-centered projects have less defects, lower cost of correcting defects, and lower warranty costs [18].

IPD implementation and using IBM in design and construction of a small commercial building (Autodesk One Market) in San Francisco, presented significant results. In that project, early participation of project stakeholders resulted to reduction of change of orders for designed models up to $0.1 \%$ of construction costs. In addition, request for information during project implementation reduced significantly. Also this project gained the platinum medal of Leadership in Energy and Environmental Design (LEED), which is considered as the highest medal in terms of sustainability and environment. This would also indicate that using IPD system compared to conventional contracts is preferable in achieving environmental standards [4].

Early participation of project key stakeholders (owner, designer, contractor, and supplier) leads to earlier completion of the project and more savings in projects $[28,50]$. In a health project with a total cost of 100 Million dollars, through IPD implementation, about \$9 Million saving in costs was achieved [15, 51]. In another example, the results obtained from evaluation in a case study (a California Hospital Project) showed that applying the IPD approach results in better implementation of risk management based on energy [52]. Considering more accurate recognition about project owner and client needs, the number of change of orders in the IPD approach is reduced [11]. In a comparison conducted about efficiency and productivity of IPD projects and non-IPD projects, indicators of efficiency and productivity of IPD projects, including speed of project delivery, achieved a higher value [53].

By applying the IPD approach in the early phases of planning and design for oil and gas projects, problems leading to time delay and increase of costs of these projects can be resolved. This is because of integration and participation of key stakeholders in the design phase. In this study, at first the reasons of oil and gas projects' delay were extracted, and then through matching capabilities of IPD with these reasons, an IPD implementation approach for oil and gas projects was suggested to reduce these problems [54]. In the next section, benefits obtained from descriptive analysis 
of the previous studies, in terms of both potential and actual benefits are introduced. These will be classified for each of the key project stakeholders. These will be the project Owner, Designer, and the Contractor.

\subsection{Classification of the IPD Benefits}

Comparing the benefits obtained from implementing the approach in actual cases of construction projects with those of the potentials coming from the available research literature, indicates that most of the stated potential benefits in the previous section, are reported as actual benefits identified through the case studies. The point to note is the small number of conducted projects thus far using this delivery system. It would seem necessary for larger projects and also projects in other fields such as oil and gas be implemented to prove the benefits obtained from it.

Figure 1 shows classification of IPD benefits for key project stakeholders, including project owner, designer, and contractor.

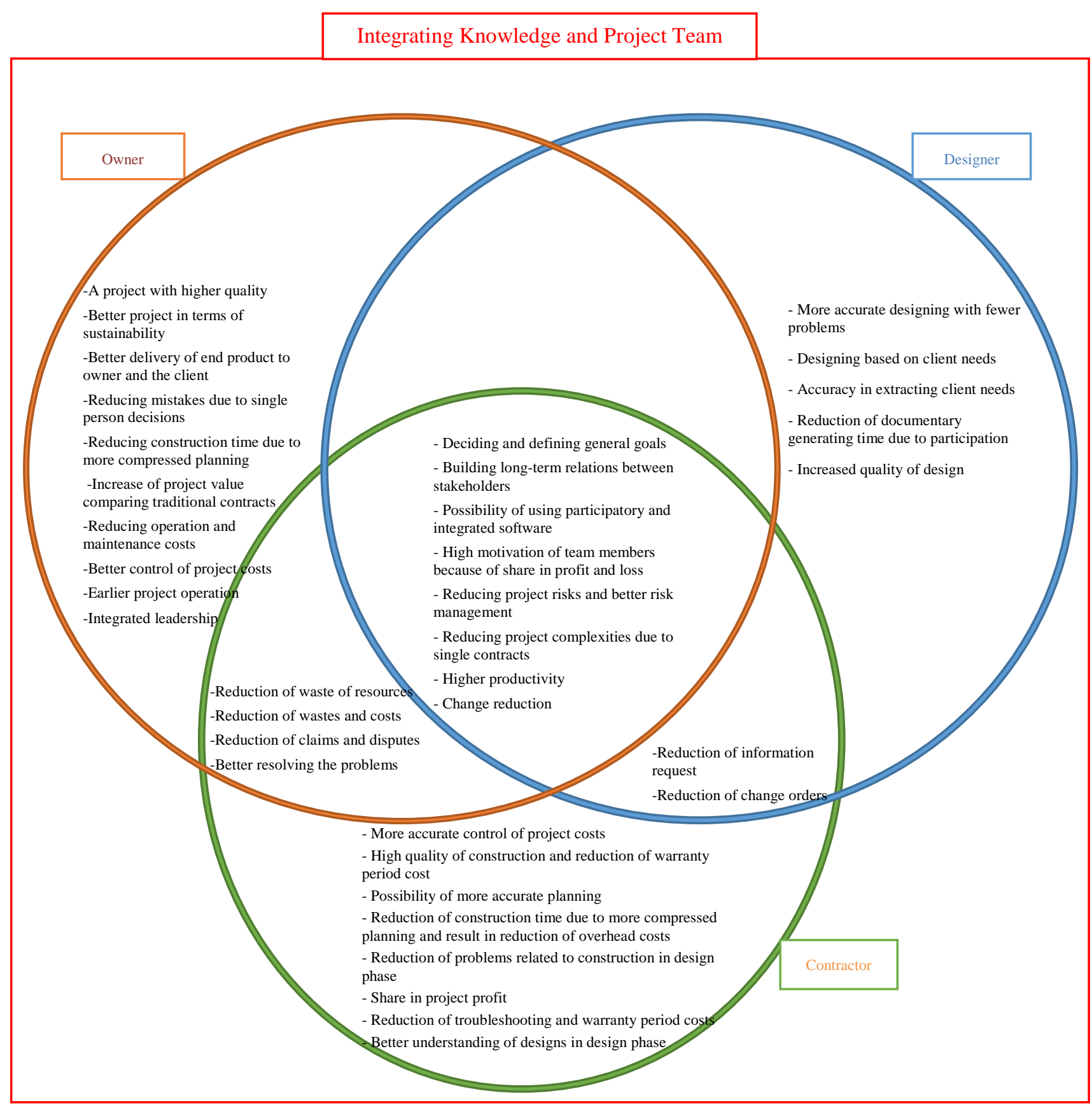

Figure 1. The framework of benefits of IPD implementation for project stakeholder

Considering the importance of the position of the project owner in the investment section, he/she will take advantage of most benefits of the IPD approach. In the project control section, better quality of product, reducing construction time, better leadership, which may have different importance for various employers, will be achieved. 
Mutually, it will have some advantages for the contractor in terms of reducing costs, detailed planning, profit sharing, and high quality of the product and other items. IPD approach has several benefits for project designer, including more precise design, design according to the needs of owner, increasing design quality, etc. Benefits such as reducing change orders and reducing information request will share advantages with the contractor, due to the presence of contractor in the early stages of design. In the following, benefits such as public decision making and objectives, creating long term relations among stakeholders, the possibility of using participatory and integrated software, etc. are also common among employer, contractor, and designer.

\subsection{Discussion}

Classification of IPD benefits for knowledge integration is important, because it helps organizations to understand their level of preparedness for implementation. In a knowledge-based economy, presenting products with low cost and high quality is considered as an important challenge. Therefore, the competitive global marketplace will be very important. This issue requires planning for the overall performance of the business, and classification of benefits is one the most important factors for its supply [55]. Classification of IPD benefits provides useful indicators for investors to encourage an extensive program in the construction industry to implement IPD. Consequently, the best methods of management have proved that project success can be presented in measuring different benefits of its implementation system. Clear and precise classification of benefits is useful for more effective monitoring and better understanding of variation range and performance of project findings [56].

Studies conducted into efficiency and productivity in the construction industry, show inefficiency and the extent of the waste of resources. With the advent of traditional methods of project delivery systems many years ago, the DBB contracts increased due to their competitive prices and having the lowest cost for project client and owner. However, the most important challenge in using the traditional delivery approaches is the isolation of design and construction phases from each other [1]. Reworks due to change of design are considered as the most common problem in increasing project costs [57]. In order to reduce such reworks, one solution is resolving separation of design from construction, and applying participative implementation systems that have higher reliability compared with traditional ones $[18,58]$. Various studies have stated utilizing participative methods are one of the solutions for improving project outputs [4].

According to the findings of this study, cases such as reducing claims, reducing the loss of resources, reducing wastes, etc. are common between the owner and the contractor. According to the results, the reduction of these cases is one of the most important goals of construction, which is of interest to stakeholders. According to the findings of this study, reduction of information request and reduction of change orders are important for the contractor and the designer, because then the project will be closer to achieving higher quality.[7] Possibility of using participatory and integrated software plays an important role because it creates the right connection between the designer and the employer [59]. Effective communication between stakeholders will ensure the project goals are achieved.

\section{Conclusion}

In the conducted studies it has been found that by increasing project integration, project results will also be improved, including sustainability, increasing labor productivity and project success indicators [22-25]. This issue puts the use of participative methods as a priority for use as a project delivery system. The highest level of integration in project delivery systems is obtained through using the IPD approach. In this approach, system, people, and commercial structure are integrated in the form of a process [1]. Using this method improves project outputs, significantly $[13,15]$.

Through adopting the IPD system, if the project owner, designer, and contractor sign the same contract, it will result in early presence of project stakeholders. In this method, selections are made based on persons' competence and is appropriate for using in projects with high complexities, such as healthcare, transportation, oil and gas projects [34]. IPD organizational structure is considerably more advanced than the former systems, so it leads to improvement of communication and reduction of delays and additional costs, which will result in legal disputes [60, 61]. According to the conducted evaluations, existence of clear relations, determining a common objective, and defining common expectations and sharing information in the entire project lifecycle, make IPD method unique [62]. As a result, the possibility of existence of hidden costs is reduced, which results in increase of risks and change orders in the traditional systems [34]. In the IPD method, one of the most important savings is in testing different sections when constructing some projects, such as healthcare projects. With early presence of stakeholders, these items are controlled and evaluated in the design section. In the healthcare projects in San Francisco, costs for initial tests were estimated as $\$ 80$ million, which were reduced to $\$ 58$ million with mutuality of construction and maintenance designers and contractors [13].

Despite all the benefits of the IPD approach found for project stakeholders, it has not still been used very widely. The reasons for this are related to lack of knowledge of project key stakeholders. Whilst other studies investigated the 
benefits of this method [45], this study is the first to classify benefits of IPD for each of the project key stakeholders (owner, designer, and contractor). In this study, the benefits of IPD implementation were investigated in two general categories composed of inherent benefits of IPD, and benefits obtained from its implementation through case studies. These benefits were classified and presented by using descriptive analysis, and by applying pattern analysis for each of the project key stakeholders. An important point is that in using IPD in the construction industry many countries have turned to systematizing and implementing IPD principles [17]. Using the IPD approach in the developed countries is growing. But despite several problems in implementing infrastructure projects, the IPD approach is still unknown. It is because these countries usually face severe fundamental problems such as cultural issues, contractual problems, lack of attention of investors to new methods of project implementation, etc. This could be due to several challenges in the approach to implementation including varying national cultural issues.

The limitations of this research are the resources used in the literature with restricted areas where IPD is currently being implemented. However, IPD has not been completely implemented. The researchers have not accessed all the information on case projects. For future studies, these classified benefits can be evaluated through case studies implemented by IPD in countries that implement IPD contracts. By examining more case studies, other potential benefits of projects can be analyzed that are developed due to their special conditions and may be reviewed in specific projects.

\section{Conflicts of Interest}

The authors declare no conflict of interest.

\section{References}

[1] AIA. “Integrated Project Delivery, a Guide.” American Institute of Architecture, (2007): 1-57.

[2] Cohen, Johnathan. "Integrated project delivery: Case studies." AIA National, AIA California Council, AGC California and McGraw-Hill (2010).

[3] Thomsen, C., and F. Faia. "Integrated project delivery: an overview." CMAA: Alexandria, VA, USA (2009): 1-28.

[4] Becerik-Gerber, Burcin, and David Kent. "Implementation of integrated project delivery and building information modeling on a small commercial project." International Journal of Project Management, (2010): 1-6.

[5] Bao, J. "The implementation of the Lean Construction BIM Based on IPD Model." Journal of Science and Technology Management Research 48, no. 3 (2013): 220-223.

[6] Bach, Marc. "The Project Coach: The New Role of the Project Manager for the Future Due to the News Tools Like Building Information Modelling, Integrated Project Delivery, Last Planner and Others." Construction and Building Research (2014): 4348. doi:10.1007/978-94-007-7790-3_6.

[7] Viana, Marina L., Bonaventura H. W. Hadikusumo, Mazlina Z. Mohammad, and Zahra Kahvandi. "Integrated Project Delivery (IPD): An Updated Review and Analysis Case Study.” Journal of Engineering, Project, and Production Management 10, no. 2 (May 1, 2020): 147-161. doi:10.2478/jeppm-2020-0017.

[8] Ilozor, Benedict D., and David J. Kelly. "Building Information Modeling and Integrated Project Delivery in the Commercial Construction Industry: A Conceptual Study.” Journal of Engineering, Project, and Production Management 2, no. 1 (January 31 , 2012): 23-36. doi:10.32738/jeppm.201201.0004.

[9] Kahvandi, Zahra, Ehsan Saghatforoush, Mahdi Alinezhad, and Farimah Noghli. "Integrated Project Delivery (IPD) Research Trends." Journal of Engineering, Project, and Production Management 7, no. 2 (July 31, 2017): 99-114. doi:10.32738/jeppm.201707.0006.

[10] Rahim, Syukran Abdul, Mohd Nasrun Mohd Nawi, and Faizatul Akmar Abdul Nifa. "Improving construction industry through integrated project delivery (IPD)." BinaTECH 1 (2015): 27-32.

[11] Collins, Wesley, and Kristen Parrish. "The Need for Integrated Project Delivery in the Public Sector." Construction Research Congress 2014 (May 13, 2014). doi:10.1061/9780784413517.074.

[12] Sindhu, Jayakrishnan, Kunhee Choi, Sarel Lavy, Zofia K. Rybkowski, Ben F. Bigelow, and Wei Li. "Effects of Front-End Planning Under Fast-Tracked Project Delivery Systems for Industrial Projects." International Journal of Construction Education and Research 14, no. 3 (February 14, 2017): 163-178. doi:10.1080/15578771.2017.1280100.

[13] The American Institute of Architects. "IPD Case Studies." School of Architecture Minnesota University. by the AIA/AIA California Council, no. March: 1-116, (2012).

[14] Autodesk. "Improving Building Industry Results through Integrated Project Delivery and Building Information Modeling." Autodesk Whitepaper, (2010): 1-12. 
[15] Sive, Ted. "Integrated project delivery: Reality and promise, a strategist's guide to understanding and marketing IPD." Society for Marketing Professional Services Foundation (2009).

[16] Elghaish, Faris, Sepehr Abrishami, and M. Reza Hosseini. "Integrated Project Delivery with Blockchain: An Automated Financial System.” Automation in Construction 114 (June 2020): 103182. doi:10.1016/j.autcon.2020.103182.

[17] Kahvandi, Zahra, Ehsan Saghatforoush, Mahdi Alinezhad, and Christopher Preece. "Analysis of Research Trends on Benefits of Implementing Integrated Project Delivery (IPD)." In International Conference on Civil, Mechanical Engineering \& Construction Management (CMC 2016), Kuala Lumpur, Malaysia, (2016).

[18] El Asmar, Mounir, and Awad S. Hanna. "Comparative analysis of integrated project delivery (IPD) cost and quality performance." Proceedings of the CIB W78 2012: 29th International Conference -Beirut, Lebanon, 17-19 October, vol. 78 (2012): 152-61.

[19] Wanigarathna, Nadeeshani, Keith Jones, Adrian Bell, and Georgios Kapogiannis. "Building Information Modelling to Support Maintenance Management of Healthcare Built Assets.” Facilities 37, no. 7/8 (May 7, 2019): 415-434. doi:10.1108/f-01-20180012 .

[20] Merriam-Webster's Collegiate ${ }^{\circledR}$. n.d. "Dictionary.” Eleventh Edition. (n.D.).

[21] Elghaish, Faris, Sepehr Abrishami, Soliman Abu Samra, Mark Gaterell, M. Reza Hosseini, and Richard Wise. "Cash Flow System Development Framework Within Integrated Project Delivery (IPD) Using BIM Tools.” International Journal of Construction Management (March 26, 2019): 1-16. doi:10.1080/15623599.2019.1573477.

[22] Molenaar, Keith, Nathaniel Sobin, D. Gransberg, T. McCuen, S. Korkmaz, and M. Horman. "Sustainable, high performance projects and project delivery methods: A state-of-practice report." White Paper for the Design-Build Institute of America and the Charles Pankow Foundation (2009).

[23] Mollaoglu-Korkmaz, Sinem, Lipika Swarup, and David Riley. "Delivering Sustainable, High-Performance Buildings: Influence of Project Delivery Methods on Integration and Project Outcomes.” Journal of Management in Engineering 29, no. 1 (January 2013): 71-78. doi:10.1061/(asce)me.1943-5479.0000114.

[24] Baiden, Bernard K., and Andrew D.F. Price. “The Effect of Integration on Project Delivery Team Effectiveness.” International Journal of Project Management 29, no. 2 (February 2011): 129-136. doi:10.1016/j.ijproman.2010.01.016.

[25] Hassan, M. E. “Assessing The Impact of Lean/Integrated Project Delivery System on Final Project Success.” Doctor of Philosophy Dissertation, George Mason University, (2013).

[26] BrookwoodGroup. "Recommended Program Management Services for a Design-Bid-Build Project.”, (2011).

[27] Li, Ying, and Timothy RB Taylor. "The impact of design rework on construction project performance." In The 29th International Conference of the System Dynamics Society, Washington, DC, (2011): 25-35.

[28] Ghassemi, Reza, and Burcin Becerik-Gerber. "Transitioning to Integrated Project Delivery: Potential barriers and lessons learned." Lean construction journal (2011): 32-52.

[29] Kahvandi, Zahra, Ehsan Saghatforoush, Mohammad Mahoud, and Christopher Preece. "Analysis of the Barriers to the Implementation of Integrated Project Delivery (IPD): A Meta-Synthesis Approach.” Journal of Engineering, Project, and Production Management 9, no. 1 (January 1, 2019): 2-11. doi:10.2478/jeppm-2019-0002.

[30] Lancaster, Franklin D., and John Tobin. "Integrated Project Delivery: Next-Generation BIM for Structural Engineering." Structures Congress 2010, Orlando, Florida, United States (May 18, 2010). doi:10.1061/41130(369)254.

[31] Pishdad-Bozorgi, Pardis, and Yvan J. Beliveau. "Symbiotic Relationships Between Integrated Project Delivery (IPD) and Trust." International Journal of Construction Education and Research 12, no. 3 (February 19, 2016): 179-192. doi:10.1080/15578771.2015.1118170.

[32] Pishdad-Bozorgi, Pardis, Ehsan Hamzanlui Moghaddam, and Yilmaz Karasulu. "Advancing target price and target value design process in IPD using BIM and risk-sharing approaches." In Proceedings of the 49th ASC Annual International Conference Proceedings, San Luis Obispo, CA, USA, (2013): 9-13.

[33] Mesa, Harrison A., Keith R. Molenaar, and Luis F. Alarcón. "Exploring Performance of the Integrated Project Delivery Process on Complex Building Projects." International Journal of Project Management 34, no. 7 (October 2016): 1089-1101. doi:10.1016/j.ijproman.2016.05.007.

[34] Basu, Ron, Chris Little, and Chris Millard. "Case Study: A Fresh Approach of the Balanced Scorecard in the Heathrow Terminal 5 Project." Measuring Business Excellence 13, no. 4 (November 13, 2009): 22-33. doi:10.1108/13683040911006765.

[35] Brady, Tim, and Andrew Davies. "From Hero to Hubris - Reconsidering the Project Management of Heathrow's Terminal 5." International Journal of Project Management 28, no. 2 (February 2010): 151-157. doi:10.1016/j.ijproman.2009.11.011. 
[36] Caldwell, Nigel D., Jens K. Roehrich, and Andrew C. Davies. "Procuring Complex Performance in Construction: London Heathrow Terminal 5 and a Private Finance Initiative Hospital." Journal of Purchasing and Supply Management 15, no. 3 (September 2009): 178-186. doi:10.1016/j.pursup.2009.05.006.

[37] Dvir, Dov, and Aaron J. Shenhar. "What great projects have in common." MIT Sloan Management Review 52, no. 3 (2011): 19-21.

[38] Naderi, E, and M Seif Naraghi. "Research Methodologies On Humanism.” Tehran: Badr Research and Publishing Center, (1996).

[39] Khaki, G. "Research Methodology.” Tehran: Derayat Publishing Institute, (2008).

[40] Erkessousi, N. El. "How Integrated Project Delivery is an Advantage to the Danish Building Industry, and how it can be executed." Bachelor Dissertation, Copenhagen Scholl of Design \& Technology, Copenhagen (October 2010).

[41] Rached, Farid, Youssef Hraoui, Antoine Karam, and Farook Hamzeh. "Implementation of IPD in the Middle East and its Challenges." Proceedings International Group for Lean Construction, Olso, Norway (June 2014): 293-304.

[42] Fish, A, and Julia Keen. "Integrated Project Delivery: The Obstacles of Implementation.” Manhattan: Master Dissertation, Kansas State University, (2011): 90-97.

[43] Kent, David C., and Burcin Becerik-Gerber. "Understanding Construction Industry Experience and Attitudes Toward Integrated Project Delivery." Journal of Construction Engineering and Management 136, no. 8 (August 2010): 815-825. doi:10.1061/(asce)co.1943-7862.0000188.

[44] Kelly, David, and B. Ilozor. "A pilot causal comparative study of project performance metrics: examining building information modeling and integrated project delivery." The Built \& Human Environment Review 6 (2013): 82-106.

[45] Salami, E. "Introduction Od Integrated Project Delivery and Likely Impacts on Pretender Cost Management in GHANA." Master Dissertation, University of Stuttgart, (2012).

[46] AIA_Trust. "Building Information Modeling and the Transition to Integrated Project Delivery." AIA Trust News, (2009).

[47] Tatum, Clyde B., and Gregory P. Luth. "Integrating Structural and Construction Engineering." Construction Research Congress 2012 (May 17, 2012): 1301-10. doi:10.1061/9780784412329.131.

[48] Choi, Jiyong, Sungmin Yun, Fernanda Leite, and Stephen P. Mulva. "Team Integration and Owner Satisfaction: Comparing Integrated Project Delivery with Construction Management at Risk in Health Care Projects.” Journal of Management in Engineering 35, no. 1 (January 2019): 1-11. doi:10.1061/(asce)me.1943-5479.0000654.

[49] Kahvandi, Zahra, Ehsan Saghatforoush, A. Zare Ravasan, and Taha Mansouri. "An FCM-Based Dynamic Modelling of Integrated Project Delivery Implementation Challenges in Construction Projects." Lean construction journal 87 (2018): 63-87.

[50] Kahvandi, Zahra, Ehsan Saghatforoush, Ahad ZareRavasan, and Christopher Preece. "Integrated Project Delivery Implementation Challenges in the Construction Industry." Civil Engineering Journal 5, no. 8 (August 21, 2019): $1672-1683$. doi:10.28991/cej-2019-03091362.

[51] Lee, Hyun Woo, Iris D. Tommelein, and Glenn Ballard. "Energy-Related Risk Management in Integrated Project Delivery." Journal of Construction Engineering and Management 139, no. 12 (December 2013). doi:10.1061/(asce)co.19437862.0000753 .

[52] El Asmar, Mounir, Awad S. Hanna, and Wei-Yin Loh. "Evaluating Integrated Project Delivery Using the Project Quarterback Rating." Journal of Construction Engineering and Management 142, no. 1 (January 2016): 04015046. doi:10.1061/(asce)co.1943-7862.0001015.

[53] Al Subaih, Adel. "Integrated Project Delivery: A Paradigm Shift for Oil and Gas Projects in the UAE and the Middle East Region.” Oil and Gas Facilities 4, no. 04 (August 1, 2015): 64-77. doi:10.2118/171722-pa.

[54] Hanks, Nicole Marie. "Investigation into the effects of project delivery methods on LEED targets." University of San Francisco USF, Scholarship Repository, Master's Projects Theses (2015).

[55] Choi, Tracy N.Y., Daniel W.M. Chan, and Albert P.C. Chan. "Perceived Benefits of Applying Pay for Safety Scheme (PFSS) in Construction - A Factor Analysis Approach.” Safety Science 49, no. 6 (July 2011): 813-823. doi:10.1016/j.ssci.2010.10.004.

[56] Zhang, Lianying, and Fei Li. "Risk/Reward Compensation Model for Integrated Project Delivery.” Engineering Economics 25, no. 5 (December 18, 2014): 558-567. doi:10.5755/j01.ee.25.5.3733.

[57] Pishdad-Bozorgi, Pardis. "Case Studies on the Role of Integrated Project Delivery (IPD) Approach on the Establishment and Promotion of Trust.” International Journal of Construction Education and Research 13, no. 2 (September 15, 2016): $102-124$. doi:10.1080/15578771.2016.1226213. 
[58] Bellido-Montesinos, Pablo, Fidel Lozano-Galant, Francisco Javier Castilla, and Jose Antonio Lozano-Galant. "Experiences Learned from an International BIM Contest: Software Use and Information Workflow Analysis to Be Published in: Journal of Building Engineering.” Journal of Building Engineering 21 (January 2019): 149-157. doi:10.1016/j.jobe.2018.10.012.

[59] Chan, A. P, D. W Chan, and J Yeung. "Relational Contracting for Construction Excellence.” Spon Press, London (2010).

[60] Ebrahimi, Ghazal, and Hadi Dowlatabadi. "Perceived Challenges in Implementing Integrated Project Delivery (IPD): Insights from Stakeholders in the U.S. and Canada for a Path Forward." International Journal of Construction Education and Research 15, no. 4 (October 4, 2018): 291-314. doi:10.1080/15578771.2018.1525446.

[61] Darrington, Joel W., and William A. Lichtig. "Rethinking the G in GMP: Why estimated maximum price contracts make sense on collaborative projects." Constr. Law. 30 (2010): 29. 